\title{
Toxic Effects Of Some Antispastic Drugs on the EEG: Some Biochemical And Immunological Studies on Rats.
}

\author{
Fathy El-Komey, Inass EL-Gaafarawi and Hanan Moustafa \\ The National Center for Social and Criminological Research, Zamalek, \\ P.O., P.C.11561, Cairo, Egypt.
}

\begin{abstract}
The toxicity of tizanidine and baclofen was studied on male rats. The oral clinical dose of tizanidine and baclofen( 0.216 and $0.54 \mathrm{mg} / 100 \mathrm{~g}$ body weight / day, respectively)was given for one, two, three and four weeks. Chronic administration of the two drugs causes damage to the lung and a significant reduction in serum and lung levels of GSH, Vit E, Vit C and SOD activity. Four weeks treatment induced significant elevation of GPX activity and MDA levels. The two drugs, also, caused inhibitory activity on proliferation of splenocyte triggered by Con A, LPS and IL-2 production cell activities. They also produced several abnormal patterns in the EEG including increased epileptiform discharges and synchronous rhythmic activity . Diffuse slowing, with increased beta and delta activity and decreased alpha activity, with superimposed beta activity were recorded. Tizanidine had more prominent effect on the EEG than baclofen .
\end{abstract}

\section{Introduction}

Antispastic drugs act on the CNS either by suppression of excitation (glutamate) enhancement of inhibition (GABA, glycine), or a combination of both. Three different categories of drugs are available: GABA- like (baclofen, benzodiazepine), central alpha 2 agonists (tizanidine, clonidine) and peripheral antispastics (dantrolene). Only four drugs are currently approved by the US FDA as antispastic agents: baclofen, diazepam, dantrolene sodium and tizanidine. It appears preferable to use centrally acting drugs such as baclofen, tizanidine, and diazepam in spasticity of spinal origin (spinal cord injury and multiple sclerosis). Intrathecal administration of antispastic drugs has been used mainly in cases of muscle over activity occurring primarily in the lower limbs in nonambulatory, severely disabled patients but new indications may emerge in spasticity of cerebral origin (Gracies et al., 1997; Kuhn, 1998 ; Karch, 2000). Baclofen remains the most commonly used antispastic for treatment of the spasticity of spinal origin (Wagstaff and Bryson, 1997; Brenner et al., 1998 ; Rode et al., 2003). Also, tizanidine appears to be a therapeutic alternative of baclofen in changing treatment (Campistal, 2003; Darrio and Tomei, 2004). Hypertonicity from spasticity or dystonia with attendant muscle spasms is often disabling. Although, baclofen and tizanidine are customarily preferred because of their fewer side effects (Meythaler et al.,1999; Illum et al., 2003 ; Dario and Tomei, 2004 and David, 2005). Intrathecal baclofen is a newer approach with reported efficacy and minimal adverse effects (Hardman et al., 1996; Meythaler et al., 1999; USPDI, 1999; Drug Facts and Comparisons, 2001).

Tizanidine and baclofen have been chosen in the current study, as both drugs are centrally acting, used in the treatment of spasticity of spinal origin and both have attracted some interest in drug addiction field, as they decrease withdrawal syndrome of some drugs of abuse (Sos et al., 2000; Ahamdi-Abhari et al., 2001; Colombo et al., 2002). In addition to the widespread use of tizanidine between addicts in Egypt (Guide book for controlled and uncontrolled drugs, 2003). 
Tizanidine, an adrenergic alpha2 agonist, has recently been introduced in the United States as a centrally acting muscle relaxant. It is a myotonolytic agent used in the treatment of spasticity from central nervous system or spinal injuries (Coward, 1994 Berkman et al., 2000; Herfindal and Gourley, 2000; Abramowicz, 2001).

Tizanidine has demonstrated many other central effects in the nervous system. For example, in genetically spastic rats, administration of tizanidine directly into the substantial nigra resulted in myotonolysis (Katzung, 2001). Abundant preclinical and clinical evidence exists for the efficacy of tizanidine as a successful reducer of increased motor tone and spasticity. Tizanidine has been shown to have abundant antinociceptive effects in animal preparations, and this action seems to be mediated via $\alpha_{2}$ adrenergic, and not opioid, receptors. It reduces central output or effectiveness of norepinephrine in central sites including the spinal cord. Pervious studies have shown antinociceptive effects of tizanidine in painful disorders and effectiveness in various headache disorders (Krusz et al., 2000). Also, adiministration of tizanidine decreased the intensity of the withdrawal symptoms in heroin dependent patients (Sos et al., 2000 ) .

The most frequent adverse tizanidine events were dry mouth, somnolence / sedation, asthenia, dizziness (Wagstaff and Bryson,1997), liver function abnormalities and hallucination (De Graaf et al.,1996). Patients should be warned of the possibility of orthostatic hypotension as well as sedation.

Baclofen is analogue of the naturally occurring neurotransmitter $\gamma$-amino butyric acid (GABA).The principal effect is to reduce the release of excitatory neurotransmitters by activation of presynaptic $\mathrm{GABA}_{\mathrm{B}}$ receptors (Miyamoto , 2004).

Baclofen, reduces the incidence of transient relaxations in response to gastric distention in humans (Lidums et al., 2000), ferrets (Blackshaw et al., 1999) and dogs (Lehmann et al., 1999\& 2000). For example, a single oral dose of baclofen inhibited the rate of transient lower esophageal sphincter (LES) relaxations and number of reflux episodes by $60 \%$ in the first hour in humans (Lidums et al., 2000).

Baclofen induces a concentrationdependent outward current in more than half of the vagal motor neurons innervating the stomach or small intestine (Browning and Travagli, 2001). Acute administration of baclofen has been reported to decrease the intravenous self-administration of cocaine (Brebner et al., 2002a ), heroin (Xi and Stein, 2002 ; Brebner et al., 2002b), nicotine (Corrigall et al., 2000, 2001; Fattore et al., 2002 ), and $\gamma$-hydroxybutyric acid (Fattore et al., 2001 ) in rats and mice, as well as to block the development of conditioned place preference to morphine (Tsuji et al., 1996 ) and methamphetamine (Li et al., 2001 ) in rats. Further, baclofen has been reported to suppress locomotors stimulation [a possible animal model of the euphorigenic properties of a psychoactive drug (Wise and Bozarth, 1987 )] induced by cocaine (Kalivas et al., 1990 ), amphetamine (Kalivas et al., 1990 ; Phillis et al., 2001 ), morphine (Woo et al., 2001 ; Leite-Morris et al., 2002 ), the opioid $\mu$-receptor agonist DAMGO (Kalivas et al., 1990 ), and phencyclidine (Menon et al., 1980 ) in rats and mice. In close agreement with the above preclinical data, baclofen has recently been reported to be effective in decreasing cocaine craving and use in cocaine addicts in an openlabel study (Ling et al., 1998 ) and preventing limbic activation, as measured by positron emission tomography, during cue-induced craving for cocaine in cocaine-dependent patients (Brebner et al., 2002a). Further, baclofen has been found to suppress the intensity of signs and symptoms of the opiate withdrawal syndrome in opiate addicts in double-blind studies (Akhondzadeh et al., 2000 ; Ahmadi-Abhari et al., 2001 ).

Wagner \& Dekin (1993, 1997) demonstrated the regulation by cAMP and activation by baclofen of $\mathrm{K}^{+}$channels in presynaptic respiratory neurons with pharmacological and biophysical characteristics similar (although not identical) to those described for background $\mathrm{K}^{+}$channels. Furthermore, background $\mathrm{K}^{+}$channels and $\mathrm{GABA}_{-\mathrm{B}}$ receptors are co-expressed in 
a variety of neuronal cell types and these findings open the possibility that $\mathrm{GABA}_{-\mathrm{B}}$ autoreceptors linked to background channels may be a general mechanism for controlling CNS excitability. The main adverse effects of oral baclofen include: sedation or somnolence weakness, vertigo and psychological disturbances. The main risks of intrathecal baclofen infusion are symptoms related to over dose or withdrawal ( Daroi and Tomei , 2004 ). Klinika (2005) reported that baclofen over dosage however may cause serious respiratory failure as also cardiac and neurological system disturbances.

\section{Aim of the Work}

The antispasticity drugs tizanidine and baclofen have attracted some interest in the drug addiction field although both caused some accidental poisoning. Therefore, the present study aimed at evaluating the toxic effects exerted by both drugs in male rats through electroencephalogrphic studies. Oxidative / antioxidative processes of the lung and some immune responses were also investigated.

\section{Material And Methods Drug:}

Sirdalud:(Tizanidine as the hydrochloride tablets), produced by Novartis Pharma S.A.E. Cairo, Egypt.

Baclofen:(Baclofen B.P.98 tablets), produced by Misr Co. for Pharma Ind. S.A.E. Mataria, Cairo. Egypt.

\footnotetext{
Animals:

Male albino rats (Rattus norvegicus) weighing 150-180g were used as experimental animals throughout the present work. They were allowed free access to food and water. Rats were randomly assigned to treatment groups of 60 rats.Each group was subdivided into four subgroups each composed of 15 animals .All animals were allowed seven days to adapt to the new cage environment. The animals (180 rats) were divided into three equal groups; each composed of 60 rats (the first as control, second and third as treated).
}

\section{Treatments:}

Treated rats received oral doses of tizanidine and baclofen $(0.216$ and $0.54 \mathrm{mg}$ / $100 \mathrm{~g}$ body weight / day, respectively) for a month. Controls received $0.1 \mathrm{ml}$ saline for the same period. 5 animals from each group were used for EEG recording. EEG recording was performed, after 2 hours from drug administration, and repeated every week for 4 weeks. 10 animals from each group were sacrificed weekly, 2 hours after drug administration at the same time of the day .These daily therapeutic doses were calculated for rats according to Paget and Barnes (1964) conversion tables .

\section{Surgical implantation of EEG electrodes:}

Surgical implantation of EEG electrodes (Skinner, 1971) was performed under ketamine anesthesia $(0.3 \mathrm{mg} / 100 \mathrm{~g}$ of body weight intraperitoneally). Cortical screw electrodes were bilaterally implanted in the skull so that one pair was in contact with the frontal cortex and the other with occipital cortex. A single screw implanted in the nasal bone. The animal was left to recover from surgery for one day before the EEG recording was performed.

\section{EEG Recording:}

For EEG recording, the animal was placed in a small plastic cage and connected to freely movable recording leads; the animal was habituated to the recording procedure several times before the actual recording was carried out. On the recording day, each animal was allowed 30 minutes to become accustomed to the recording situation. Each animal was left in the recording cage and an EEG for 15-20 minutes was recorded.

\section{EEG Analysis:}

EEG data were analyzed at three levels according to Saleh et al.(1983). First, the EEG record was visually screened and any unusual signs of activity were identified. Most important among these are spikes, spindles and very slow activity. At the second level of the analysis the activity or activities dominating the EEG were determined in one-second-time segment 
and examined every ten seconds of the record. The period and amplitude of this frequency were carefully measured, in reference to EEG calibration signals, which were made several times during every recording session. Finally, randomly chosen long segments were subjected to manual spectral analysis by measuring the percentage of time occupied by different EEG frequency band.

\section{Collection of serum samples :}

Blood samples were collected in conical glass centrifuge tubes and left for about one hour in the refrigerator for clotting. Sera were then separated by centrifugation at 1500 r.p.m. for 10 minutes and kept at $-80^{\circ} \mathrm{C}$.

\section{Sample Preparation for Biochemical Analysis:}

After decapitation, rats were dissected and the lung was rapidly removed, weighed and saved at $-80^{\circ} \mathrm{C}$ until analysis. Accurately weighed portions were homogenized in saline using electrical homogenizer to give a final dilution of $10 \%$ tissue in saline solution .

\section{Biochemical Analysis :}

\section{1. lipid peroxide : Malondialdehyde (MDA) :}

Lipid peroxide levels were estimated by the thiobarbituric acid reactive substance (TBARS) by the assessement of malondialdehyde level using the method of Albro et al. (1986).

\section{Reduced glutathione (GSH) :}

The determination of GSH based on the reaction with $5,5^{-}$- dithiobis - 2nitrobenzoic acid to give yellow compound (Tietz, 1986).

\section{Glutathione peroxidase activity (GPX) : \\ GPX activity was measured using} Ransel glutathione peroxidase kit based on the method of Paglia and Valentine (1967).

\section{Superoxide dismutase activity (SOD)}

SOD activity was measured using Ransel Kit based on the method of Suttle (1986).

\section{Vitamin E (Vit E) :}

Vitamin E was estimated by the method of Varely et al. (1981) where dipyridyl and ferric chloride were added to an aliquot of n-propanol .

\section{Vitamin $\mathbf{C}$ (Vit C):}

Ascorbic acid (Vit C) was determined according to the method of Tietz (1986) where oxidized ascorbic acid reacts with acidic 2,4- dinitrophenyl- hydrazine to form red bis- hydrazone .

\section{Histological studies:}

Animals were sacrificed every week, lung was picked out and fixed in 10\% neutral formalin. Paraffin sections of 7 micrometer thickness were prepared and stained by $\mathrm{Hx}$ and Eosin for morphological study (Drury and Wellington, 1980) and by Orcein (Drury and Wellington, 1979).

\section{Splenocytes Preparation}

All spleen was aseptically removed and teased on a steel mesh immersed in Roswell Park Memorial Institute-1640 (RPMI-1640) $\quad / 100 \mu / \mathrm{ml}$ penicillin $/ 100$ $\mu \mathrm{g} / \mathrm{ml}$, strepto-mycin/200 mM Gultamine/ $100 \mathrm{mM}$ Na pyruvate in a plastic dish. The cells that passed through the mesh were washed twice with RPMI-1640.The erythrocytes were lysed with double distilled water, while the remaining cells were resuspended in RPMI-1640 with 5\% normal human serum (NHS, Sigma).

\section{Assay of cell proliferation:}

MTT [(3, 4, 5-dimethyl thiazoyl-2-yl) 2, 5-diphenyl tetrazolium bromide] colorimetric analysis was used to measure the proliferation rate of splenocyte of rat. Briefly, spleen cells were suspended in RPMI-1640 supplemented by 5\% normal human serum (NHS, Sigma).The final concentration of the spleen cells was $3 \times 10^{6}$ cells $/ \mathrm{ml}$ for conconvalin-A (ConA,Sigma) $(5,10 \mu \mathrm{g} / \mathrm{ml})$ and lipopoly saccharide( LPS, Sigma) $(5,10 \mu \mathrm{g} / \mathrm{ml})$. Each of the flatbottom microtiter plates (Nunc) used in the assay contained $100 \mu \mathrm{L}$ of diluted cells combined with $100 \mu \mathrm{L}$ of mitogen or $100 \mu \mathrm{L}$ of culture medium. After four days of 
incubation at $37^{\circ} \mathrm{C}, 5 \% \quad \mathrm{CO}_{2}, 5 \mathrm{~g} / \mathrm{L}$ MTT $40 \mu$ was added to each and cultured for another 4 hours. The solubilization stop solution is then added to the culture wells to solubilize the formazan product and the absorbance at $570 \mathrm{~nm}$ was recorded using a 96 well plate reader. Stimulation index (SI) $=$ mean $\mathrm{cpm}$ of triplicate test cultures/mean cpm of corresponding replicate control rat. The original form of this assay was described by Mosmann (1983).

\section{Cytokine Production:}

IL-2 is a T-cell growth factor produced by stimulated $\mathrm{T}$ lymphocytes.

To test the IL-2 producing ability of $\mathrm{T}$ cell, $6 \times 10^{6}$ splenic leukocytes in $1 \mathrm{ml}$ of media were incubated with $0,5.0 \mathrm{mg} / \mathrm{ml}$ Con A for 18 hours at $37^{\circ} \mathrm{C}$ in humidified $5 \% \mathrm{CO}_{2}$ and $\mathrm{O}_{2}(95 \%)$ incubator, after which supernatants were collected and saved at $-80^{\circ} \mathrm{C}$ until used for cytokine determination.

\section{Cytokine Determination:}

The amount of $\mathrm{IL}-2$ in culture supernatants were determined using sandwich enzyme linked immunosorbent assays (ELISA) using immunoassay Kit (Biosource). The resulting yellow color was measured using the UV max ELISA plate reader (Molecular Devices Corp.). Means \pm SD of triplicates of control cultures were then calculated and subtracted from those of test cultures.

\section{Statistical analysis: -}

Statistical analysis of the results was calculated using Student's t- test.

\section{Results And Discussion}

The EEG results (amplitude, total frequencies and percent wave composition) after daily administration of tizanidine and baclofen, are shown in Table (1) and Figure (1).

Tizanidine was found the elicit an increase in the frequency which was interrupted by slow waves, but still there was an increase in the frequency throughout the experiment in the motor area. At the same time, the amplitude began to decrease until the end of the first three weeks then began to return to nearly control value after four weeks. Baclofen, on the other hand, induced inhibition of the amplitude of the motor area throughout the first two weeks ; but at the third and forth weeks it began to return to control value.

On the other hand, the change of frequency was increased in the first two weeks more than in the third and forth weeks .The effects on the visual centers; were contradictory, tizanidine caused an increase in the amplitude over the control value of 3.3 to 4.7 and 5.0 at the first two weeks but at the third week it caused a decrease to 2.9 and returned back to normal value at the forth week. Baclofen, on the other hand caused a drop in amplitude from the control value at the first two weeks, but at the third and forth weeks it increased above the control value.These results agreed with Mandema (1992) who reported the baclofen-induced decrease in amplitudes in the 11.5 to $30 \mathrm{~Hz}$ frequency band used as an EEG effect measure ( David, 2005). As to the differences between EEG tracings of the other two brain regions, they were intermediate between the two former regions.

The over-whelming phenomenon was that both tizanidine and baclofen affect the percent wave - composition of the motor area in such a way that; delta waves increased from nil to values of $22 \%$ for tizanidine and $10 \%$ in case of baclofen. The disappearance of most of the alpha waves and the appearance of the beta waves in motor area.

On the other hand, the effects of these two drugs on the visual centers wave composition were different from those reported on the motor centers. Therefore, while the decreases in alpha wave percent were of high magnitude in tizanidine treatment (from $80 \%$ to 3\%), baclofen produced moderate magnitude (from 80 to 16) and increased delta, theta and beta wave composition. Therefore, the change in wave composition in tizanidine is more than baclofen. These results differ from those of Beard et al.(2005) who reported that tizanidine (Zanaflex) was more 
effective than other drugs such as baclofen and has a slightly different profile of sideeffects. Despite claims that it causes less muscle weakness, there was very little evidence that tizanidine performed any better in this respect than other drugs, although it is more expensive. These results agree with Landau (1995);Mycek et al.(1997) and Krusz et al .(2000). This comparison shows that Tizanidine was more effective than Baclofen.

In other words, a good part of the alpha-waves which constitutes the major portion of the control EEG-waves disappeared to give way to the appearance of delta and to the noticeable increase in the percent of beta waves. However, up on treatment with the two drugs for four weeks, this fast activity became superimposed with numerous abnormal activities. Most of these abnormal patterns were with the delta wave and slower as well as several complex patterns including spikes and wave complexes. Most of these abnormal patterns are normally correlated with temporary or permanent structural and functional damage of neural structures (Sphelmann, 1980, Saleh and El-Kashef, 1982 ; Klemm, 1969\& 1992). These patterns are often reported in animals suffering from structural brain damage due to severe intoxication with several drugs.

In addition, several cases of EEG bilateral symmetry were observed in our study. This indicates a major disturbance in the interaction between the two sides of the brain possibly as a result of a specificinsalt on conduction systems between the two hemispheres or either within one or both of them (Schaul et al., 1986; Brenner and Schaul, 1990).

Our results showed that three distinct stages of tizanidine effects were observed, an initial CNS excite followed by a sedative state, and finally by convulsive generalized electrographic seizures. Tizanidine, also, caused abnormal patterns (focal ictal dischargs and epileptic forms). On the other hand, baclofen showed the same stages effects, but the sedative stage was more than in the case of tizanidine. These results agree with Elaine et al.(1998) who reported that significant locomotor depression was observed after administration of 2.5 and $5 \mathrm{mg} / \mathrm{kg}$ baclofen in SLOW-1 mice, but only after $5 \mathrm{mg} / \mathrm{kg}$ in FAST-1 mice seizures were induced.

These patterns consisted of ictal generalized spike and wave discharged complexes, forming irregular waves. These drugs generally increase the voltage of slow activity, decreases the frequency of the alpha rhythm, and increase beta activity. Our results agree with Endmann and Kutz (2005) who reported that the EEG shows a high degree of continuous irregular slow waves over both hemispheres in the delta and theta activity range due to administration baclofen. This gives reason to assume encephalitis.

The effects of the two drugs have suggested that the combination of increased slow activity and increased beta activity is characteristic, suggesting sedative effects. Similar findings occur in the two sides of the brain except that beta activity was decreased. These drugs caused synchronous rhythmic activity, focal sharp waves, spikes, spike and wave complexes and wave activity, and paroxysmal delta activity. Focal and other epileptiform abnormalities, as well as seizures, occur frequently during the first two weeks.

The patterns of localized epileptiform activity consisted of single of repetitive focal spikes sharp waves and their combination, with slow waves these produce partial damage in circumscribed cortex area. Acute focal epileptiform activity is produced by Varity kind's cerebral lesions (Sphelmann, 1980).

Data represented in Table (2) indicate a significant reduction in serum levels of GSH, Vit E, Vit C and SOD activity. There was also significant elevation of GPX activity and MDA levels in tizanidine and baclofentreated rats through 4 weeks treatment period.

Table (3) showed the effect of both drugs on the same parameters in the rat lung. The data revealed a significant reduction in GSH, Vit E, Vit C levels, SOD activity and a significant increase in GPX activity and MDA levels on $2^{\text {nd }}, 3^{\text {rd }}$ and $4^{\text {th }}$ 
weeks of treatment. There was no significant effect observed on the $1^{\text {st }}$ week of treatment except the reduction of Vit $\mathrm{E}$ levels. The effect of tizanidine on lung antioxidants level is more pronounced than that of baclofen .

Comhair and Erzurum (2002) reported that lung diseases occur in response to oxidative and nitrosative stress. The lung ability to respond to oxidative stress depends largely on its capacity to up- regulate protective antioxidant capacity

Oxidative stress can result in oxidation of cellular constituents such as low molecular weight thiol-containing compounds including glutathione, protein thiols, as well as, other functional groups on macromolecules and peroxidation of lipids and other susceptible cellular constituents (Reed, 2001).

In the present study the two muscle relaxant drugs, tizanidine and Baclofen elevated lipid peroxide (MDA) levels and depleted reduced glutathione (GSH) in rats serum and lung throughout four weeks treatment. This was in accordance with Koul et al. (2001) and Ermis et al.(2005) who reported the depletion of GSH with an increase in MDA levels after exposure to cigarette smoke, a variety of substances such as allergens, certain chemicals as nitrogen mustards (cancer chemotherapeutic agent), acetaminophen [an analgesic drug] (Reed, 2001) and in asthma (wood et al. 2003).

All tissues and cells contain defense systems for detoxification of biological reactive intermediates of oxygen to prevent cellular damage. Formation of $\mathrm{H}_{2} \mathrm{O}_{2}$ leads to the consumption of GSH as glutathione peroxidase (GPX) activity transforms the $\mathrm{H}_{2} \mathrm{O}_{2}$ to $\mathrm{H}_{2} \mathrm{O}$ and $\mathrm{GSH}$ to GSSG (Reed, 2001). SOD and GPX form an important part of the antioxidant defense system. SOD catalyses the dismulation of $\mathrm{O}_{2}^{-}$into oxygen and hydroperoxide which is then acted upon by GPX to form $\mathrm{H}_{2} \mathrm{O}_{2}$. SOD activity has been reported to be increased, decreased, or unchanged in asthmatics compared with controls. GPX activity has been reported to be decreased or unchanged in asthmatics (Wood et al., 2003) and in human peripheral blood mononuclear cells exposed to trace elements (Kuppusamy et al., 2005). The present results indicate the elevation of GPX activity and the reduction of SOD activity after tizanidine and baclofen administration for a month in the serum and lung of male rats. Therefore, the current results are in accordance with the previous results .

Vitamin $\mathrm{C}$ and $\mathrm{E}$ are powerful nonenzymatic antioxidants, free radical scavengers and are well known inhibitors of lipid peroxidation. Vit $\mathrm{E}$ is integrated into cell membranes where it can protect against the peroxidation of membrane lipids. GSH and ascorbic acid ( Vit C) are thought to be the reducing agents that regenerate the oxidized form of Vit $\mathrm{E}$ (Henderson and Nikula, 2001).

In the present study Vit $\mathrm{E}$ and $\mathrm{C}$ levels were reduced significantly after tizanidine and baclofen treatment. This suggests that oxidative stress in the form of elevated lipid peroxides together with impaired antioxidant defense system may play a role in lung lesions that occurre after tizanidine and baclofen treatment for a month .

Although tizanidine and baclofen are not known to be converted to toxic metabolites by lung tissue. Both drugs exert their effects on the lung oxidative/ antioxidative process. Hodgson and Levi (2001) reported that the liver may activate chemicals that can be transported to distant tissues and produce toxicity or it may be the primary target organ depending on the dose such as toxicity produced by monocrotaline (MCT). MCT pneumo- toxicity is of particular interest because it has been used as an animal model for certain human chronic pulmonary diseases. When MCT was given (in high doses) to rats or other animals, pronounced liver injury occurred. Lower doses, that are only mildly hepatotoxic, result in lung injury and usually associated with death within several weeks.

Figure (2.1.A) shows the lung picture of untreated rat(control) with normal alveoli and bronchi and blood vessels .

Administration of tizanidine induced dense peribronchial lymphocytic infiltration and vascular dilatation with haemorrhage seen in Figures (2.1.B\&C ). Lung consolidation is also seen in Figures (2 
.2.B\&D and 2.3.A).Figure (2.4.B) shows atrophy in lung treated with tizanidine (B) compared with control in figure (2.4.A). Addition of baclofen shows a decrease of peribronchial lymphocytic infiltration without consolidation or haemorrhage (Figure 2.1.c , 2.2.A\&Cand 2.3.B ).

Morphological changes in the lung, after administration of tizanidine, were dense peribronchial lymphocytic infiltration, consolidation, vascular dilatation and haemorrhage. Baclofen also caused cellular and vascular changes but less than tizanidine. Nabila et al. (2001) reported that the lungs of rats treated with the drug (pyriproxifen) revealed marked congestion, cellular infiltration and thickening of interalveolar septa. The present study coincided with those of Strivastava (1984) who studied the biochemical and pathological effects of fly ash on the lung, liver and blood of rats.

As shown in Table (4) the cellularity of the spleen was highly significantly suppressed in rat during the early period of treatment with either drugs. There was statistically significant difference after long-term administration of baclofen and tizanidine compared with that of the saline control group.

The results of Con A $(5,10 \mu \mathrm{g} / \mathrm{ml})$ stimulated splenic lymphocytes showed significant enhancement during the period of baclofen treatment as compared to control rats, Table (4).

The results of LPS $(5,10 \mu \mathrm{g} / \mathrm{ml})$ stimulated splenic lymphocytes showed that a significant interaction between the administration of baclofen and LPS responses, with a significant increase during the first three weeks of treatment. After that, a general decline in the proliferative respo-nse was recorded at the four week of treatment as compared with control rats.

The results of ConA $(5,10 \mu \mathrm{g} / \mathrm{ml})$ stimulated splenic lymphocytes showed that there was a significant decrease throughout the period of administration of tizanidine as compared to the salinecontrol rats (Table 4).

The results of LPS $(5,10 \mu \mathrm{g} / \mathrm{ml})$ stimulated splenic lymphocytes showed significant difference during the period after tizanidine treatment(Table 4).

The suppressive effect of drug increased in a time and dose- dependent manner when compared with that of the saline control rats (Table 4).

The results of the IL-2 production using ConA $(5 \mu \mathrm{g} / \mathrm{ml})$-stimulated splenic lymphocytes showed that daily administration of baclofen induced a highly significant suppression in the production of IL-2 during the period of treatment.

Also, the administration of tizanidine induced a highly significant suppression in the production of $\mathrm{IL}-2$ using ConA $(5 \mu \mathrm{g} / \mathrm{ml})$-stimulated splenic lymphocytes during the first three weeks. However, there was a significant interaction between tizanidine and production of IL-2 which significantly increased during the four week of chronic treatment compared with the saline control rat ( Table 5).

The importance of immunomodulatory effects of different drugs of abuse on increased susceptibility of drug abusers to infections is well documented (Levy, 1989; Donahoe, 1990; Karch, 1993 ; Kalashniltov et al., 2002).Thus, the possible effects of baclofen and tizanidine on some immunological parameters, were included in the present study. The results showed inhibitory activity of tizanidine on proliferation of splenocyte triggered by Con A, LPS and IL-2 production cell activities. The results in $\operatorname{Tables}(4 \& 5)$ also showed a significant increase after baclofen on proliferation of splenocyte induced by Con A, LPS at the early stage of treatment, then significant decrease at the last period of treatment. However, there was decrease of IL-2 production at the first three weeks, followed by an increase in the last week after long administration.

These results showed that, baclofen and tizanidine-induced effects resemble those of diazepam in in vitro and in vivo studies (Wang et al.,1984; Sclumpf et al., 1990 \& 1992; Ramseier et al., 1993; Mediratta and Sharma, 2002). Chan et al. ( 1993) reported that the evaluated serum soluble IL-2 receptor (sIL-2R), a marker of T-lymphocyte activation in vivo, could be 
useful to monitor disease activity in asthma.Serum IL-2R level was significantly higher in an acute asthma than in stable disease.

Low levels of glutathione in the current study supported the reduction of IL -2 where Comhair and Erzurum, 2002 reported that the glutathione system is altered in lung inflammatory conditions. Levels of glutathione modulate the $\mathrm{T}$ helper type 1 (Th1) vs. the Th2 immune response pattern. For example, high levels of glutathione in patients with chronic beryllium disease (CBD) may contribute to development and/or maintenance of a chronic Th1 cell-mediated (contains IL-2) immune response to beryllium, whereas low GSH levels may contribute to the development or maintenance of $\mathrm{Th} 2$ cell immune response in asthma.

Considering the effect of tizanidine and baclofen on the immunological paramters tested in this study(Table 4\&5) showed that these drugs may contribute to the susceptibility of drug addicts to infectious diseases. Further investigation may reveal the mechanisms by which these drugs affect immunological param-eters. and further studies are needed to confirm these observations.

In conclusion tizanidine and baclofen, in the used doses for four weeks, caused damage to lungs, inhibitory activity on proliferation of splenocyte triggered by Con A, LPS and IL-2 production cell activities and, thus, may increase susceptibility of drug abusers to infectious diseases. The two drugs produced several abnormal patterns including increase epileptiform discharges and synchronous rhythmic activity of the rat EEG. The two drugs produced diffuse slowing, with increased beta and delta activity and decreased alpha activity, with superimposed beta activity. Tizanidine was more effective than baclofen. Therefore, these drugs must be used with strict health precautions, and it is favorable to take antioxidants (Vit $\mathrm{E}$ and $\mathrm{C}$ ) during using such drugs. 
Fathy El-Komey et al 
Toxic Effects Of Some Antispastic Drugs on the EEG............ 
Fathy El-Komey et al 


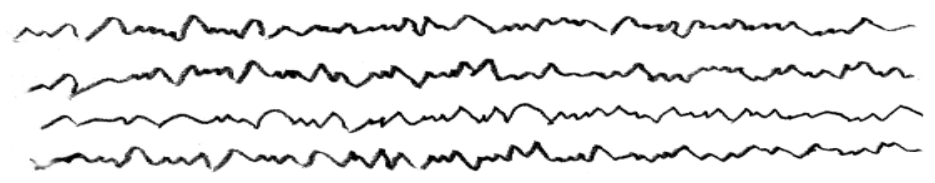

Control

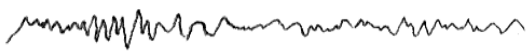

$$
\begin{aligned}
& \text { varngrarar }
\end{aligned}
$$

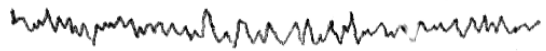

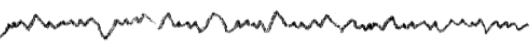

EEG of tizanidine after one week

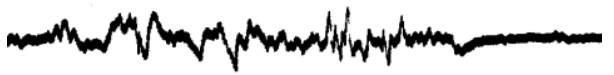

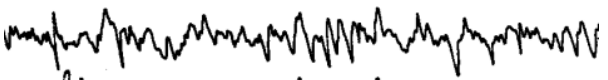

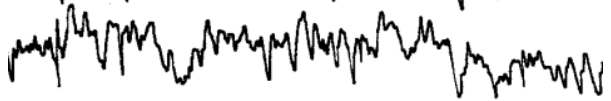

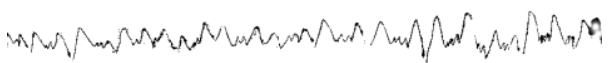

EEG of tizanidine after two weeks
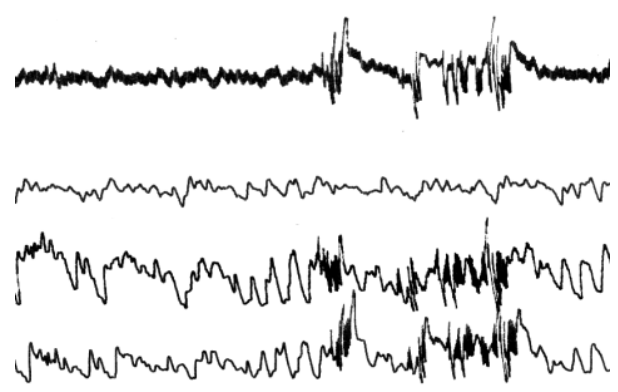

EEG of tizanidine after three weeks

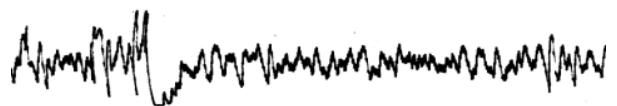

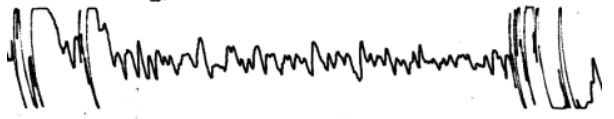

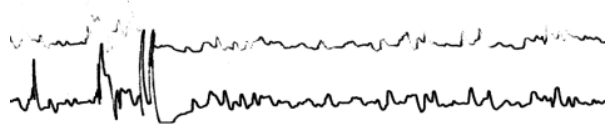

EEG of tizanidine after four weeks

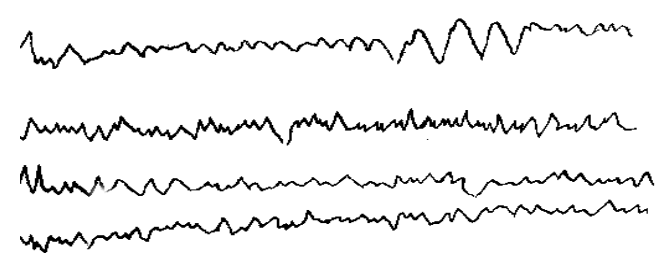

EEG of baclofen after one week
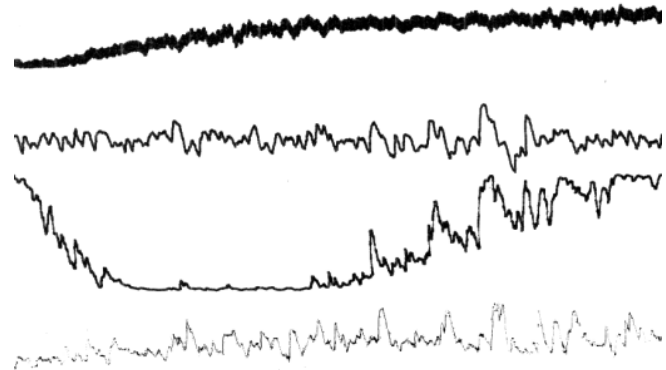

EEG of baclofen after two weeks

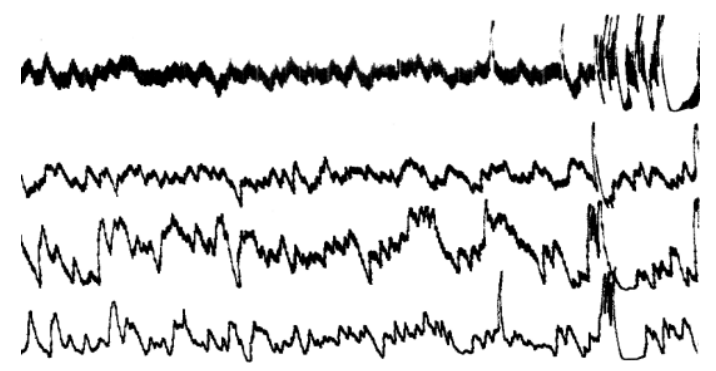

EEG of baclofen after three weeks

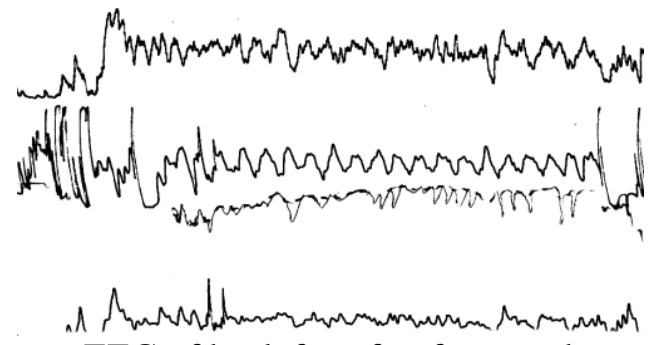

EEG of baclofen after four weeks

Figure (1): Electroencephalogram of an awake, moving rat showing bursts of polyspikes associated with irregular slow activity and sharp spike and polspikes in three and four weeks after treatment with tizanidine and baclofen.

Electrode arrangements are:A=Right motor-left motor; $\mathrm{B}=$ Right visual-Left visual;C=Right motor-Right visual; $\mathrm{D}=$ Left motor-left visual.

Calibrations: $\lrcorner=1 \mathrm{~mm}=12.5 \mathrm{uv} / 1 \mathrm{sec}$. 


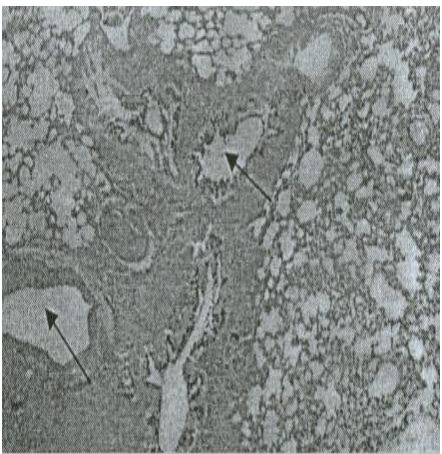

A(Lung control)

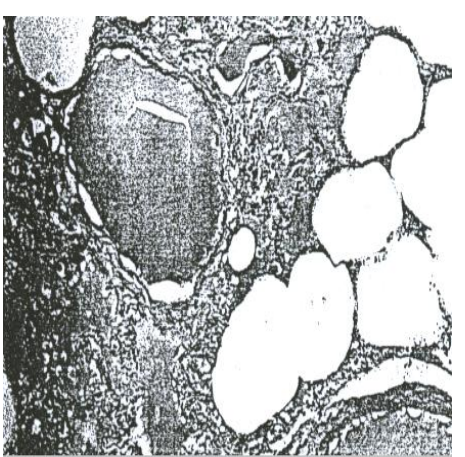

$\mathbf{B}$ (Lung treated with tizanidine) $\mathbf{C}$ (lungtreated with tizanidine)

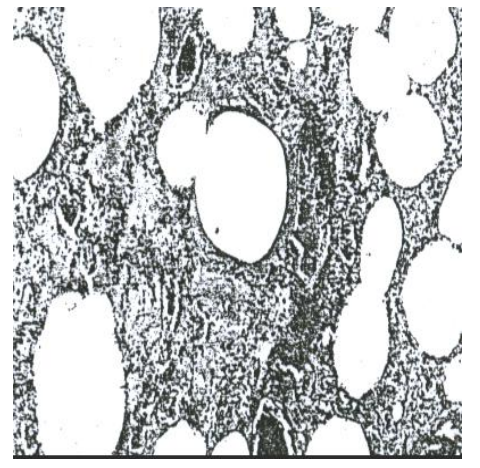

Figure( 2.1 ):Transverse Section(T.S.) in the rat lung showing in (A):Normal bronchi and blood vessels;(B): thickening and exudates in the inter- alveolar spaces; (C): lung congestion and oedema(H\&E).

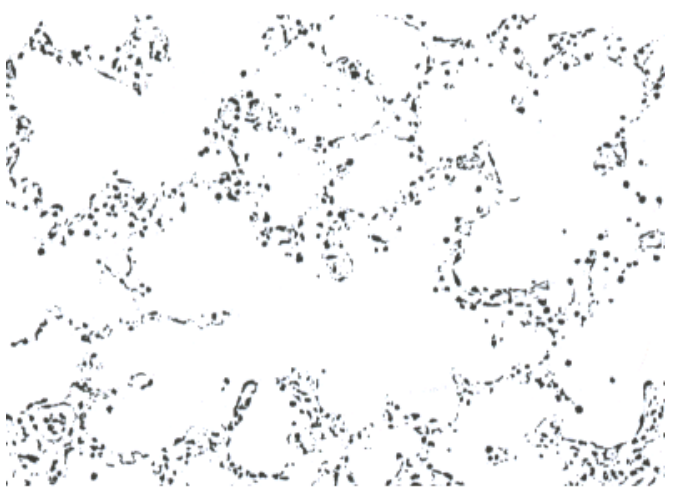

A (Lung treated with baclofen)

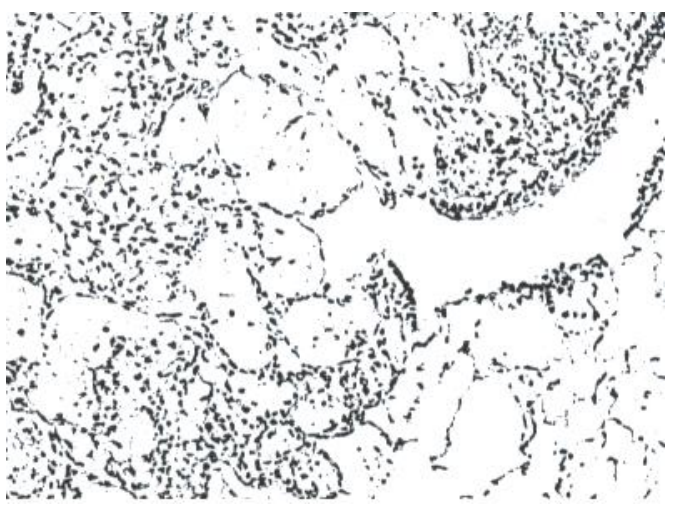

C (Lung treated with baclofen)

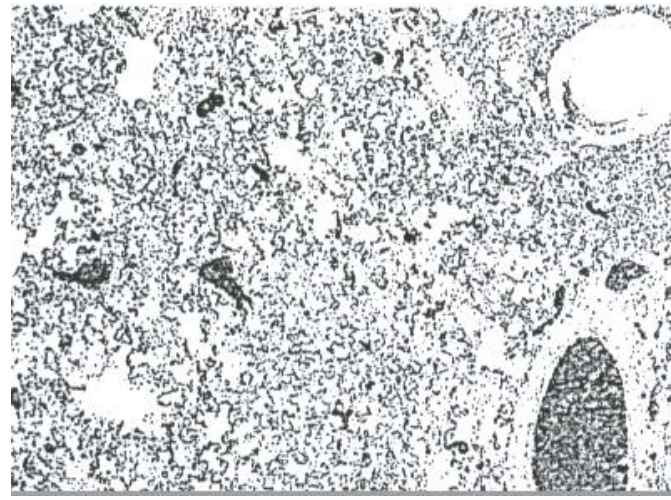

B (Lung treated with tizanidine)

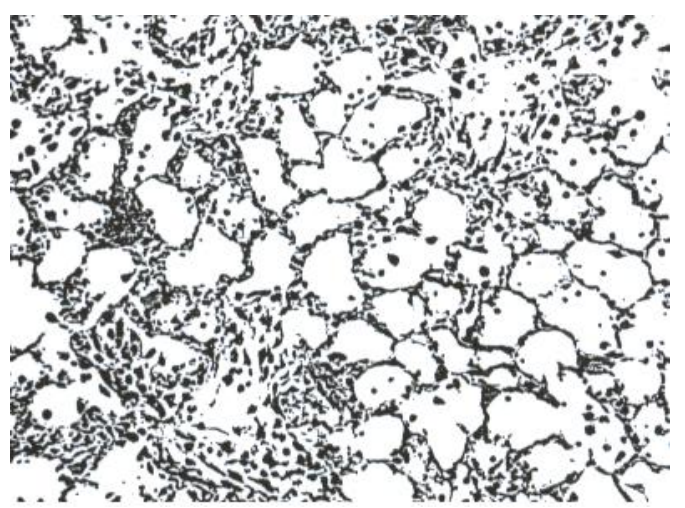

$\mathrm{D}$ (Lung treated with tizanidine)

Figure( 2.2 ):Transverse Section(T.S.) in the rat lung showing in (A):Pulmonary oedema an chronic treatment with Bclofen, a slight inflammatory reaction is present but little evidence of degenerative change is detected;(B): Pulmonary oedema an chronic treatment with tizanidine ,showed lesion is associated with a pronounced inflammatory reaction and congestion;(C): Pulmonary oedema an chronic treatment with baclofen induced macrophage degeneration and an associated inflammatory cell infiltration;(D): Pulmonary oedema an chronic treatment with tizanidine showing congestion, inflammation, alveolar wall degeneration and focal fibroblast proliferation.(H\&E). 


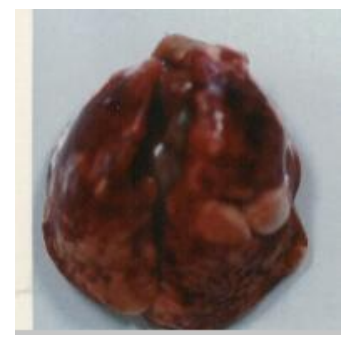

A

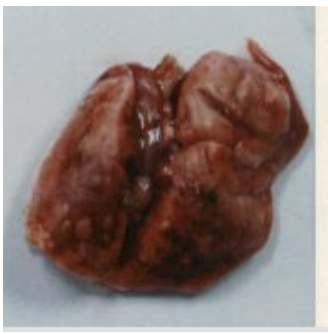

B

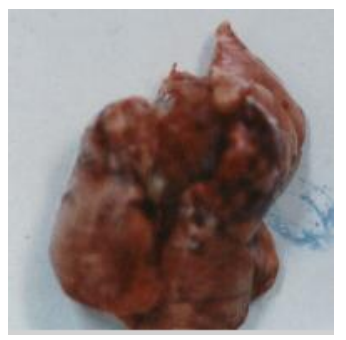

C

Figure (2.3): Lung treated with tizanidine shows hemorrhage

(bleeding) $(\mathrm{A} \& \mathrm{~B}) ; \mathrm{C}$ shows lung treated with baclofen hemorrhage

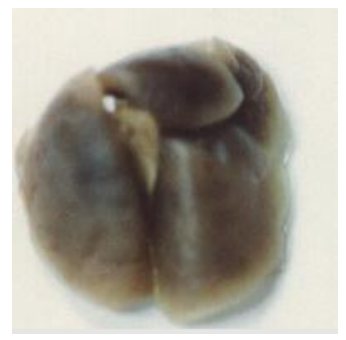

A

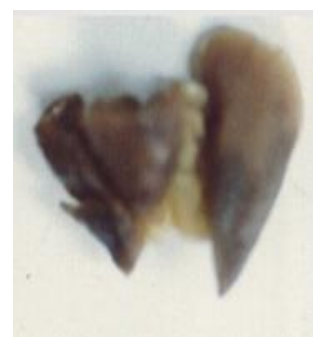

B

Figure (2.4)Lung treated with tizanidine shows atrophy in B,compared with control in A .

\section{Reference}

1. Abramowicz,M. (ed) (2001): The Medical Letter Drugs of Choice 14th edition, New Rochelle, NY: The Medical Letter, Inc.

2. Ahmadi-Abhari, S. A.; S. Akhondzadeh; S.M. Assadi; O.L. Shabestari; Z.M. Farzanehgan and A.Kamlipour (2001): Baclofen versus clonidine in the treatment of opiates withdrawal, sideeffects aspect: a doubleblind randomized controlled trial. Journal of Clinical Pharmacy and Therapeutics., 26(1): 67-71.

3. Albro P.W., J.T.Corbett and J.l. Schroder (1986) : Application of the thiobarbituric assay to measurement of lipid peroxidation products in microsomes, J. Biochem. Biophys. Methods. , 13:185 .

4. Akhondzadeh, S.; S.A. Ahmadi-Abhari; S. M. Assadi; O.L. Shabestari; A.R. Kashani and Z.M. Farzanehgan (2000): Double-blind randomized controlled trial of baclofen vs. clonidine in the treatment of opiates withdrawal. Journal of Clinical Pharmacy and Therapeutics 25, 347-353.

5. Beard, S.; A. Hunn and J. Wight (2005): Treatments for spasticity and pain in multiple sclerosis: a systematic review. School of Health and Related Research (ScHARR), University of Sheffield, UK.

6. Berkman MK. , T. Erbengi , T.San and A. Sav (2000) : The effect of tizanidine on chronic vasospasm in rats . Acta Neurochir (Wien), 142(9): 1047 -1054 .

7. Bertrand, S.; F. Morin and J.C. Lacaille (2003): Different actions of gabapentin and baclofen in hippocampus from weaver mice. Hippocampus. 2003; 13(4):525-8.

8. Blackshaw, L.A.; E. Staunton ; A. Lehmann and J. Dent ( 1999): Inhibition of transient lower esophageal sphincter relaxations and reflux in ferrets by GABAB receptor ligands. Am J Physiology ; 277:G867-874.

9. Brebner, K.; A.R. Childress and D.C.S. Roberts (2002a): A potential role for $\mathrm{GABA}_{\mathrm{B}}$ agonists in the treatment of psychostimulant addiction. Alcohol and Alcoholism 37, 478-484.

10. Brebner,K.; W. Froestl and D.C.S. Roberts (2002b): The $\mathrm{GABA}_{\mathrm{B}}$ antagonist CGP56433A attenuates the effect of baclofen on cocaine but not heroin self-adm- 
inistration in the rat. Psychopharmacology 160, 49-55

11. Brenner, R.P.; and N. Schaul (1990): Periodic EEG patterns: classification, clinical correlation, and pathophysiology. J Clin Neurophysiology; 7(2): 249-267.

12. Brenner R. ,N. Hyman, R.Knobler ,M. O'Brien and T.Stephan (1998) : An approach to switching patients from baclofen to tizanidine. Hosp.Med., 59 (10):778- 782

13. Browning, K.N. and R.A. Travagli (2001): $\mathrm{GABA}_{\mathrm{B}}$ receptor activation uncovers neuronal diversity in the rat dorsal motor nucleus of the vagus (DMV). Am J Physiology. 210-218.

14. Campistol, J. (2003) : Orally administered drugs in the treatment of spasticity . Rev. Neurol ., 37 (1) : $70-74$.

15. Chan C.k.w. , Leung C.H.S. and laikar neng J.C.K. (1993) : Serum concentration of soluble interleuk in 2 receptors in asthma,Correlation with disease activity, Chest.

16. Colombo G. , S. Serra ,G. Brunetti , G.Atzori, M.Pani ,G. Vacca,W. Froestl, M.A.Carai and G.L.Gessa (2002) : the $\mathrm{GABA}_{\mathrm{B}}$ receptor agonists bacl-ofen and GGP 44532 prevent Acquisition of alcohol drinking behaviour in alcohol- preferring rats, Alcohol and Alcoholism, 37 (5): $499-$ 513 .

17. Comhair, S.A.A. and S.C. Erzurum (2002) : Antioxidant responses to oxidant mediated lung diseases, Am J. Physiol . Lung Cell Mol. Physiol., 283 :L246- L 255

18. Corrigall, W. A.; K.M. Coen; K.L. Adamson;b.L.C.Chow and J. Zhang (2000): Response of nicotine self-administration in the rat to manipulations of muopioid and -aminobutyric acid receptors in the ventral tegmental area. Psychopharmacology; 149, 107-114.

19. Corrigall, W. A.;K.M. Coen; J. Zhang and K.L. Adamson (2001): GABA mechanisms in the pedunculopontine tegmental nucleus influence particular aspects of nicotine self-administration selectively in the rat.Psychopharmacology,158,190-197.

20. Coward,D.M.(1994): Tizanidine: Neuropharmacology and Mechanism of Action. Neurology,44(1)Supply9):S6-10; discussion S10-11.

21. Dario A.and G.Tomei (2004) : A benefitrisk assessment of baclofen in severe spinal spasticity . Drug Saf., 27 (11) : $799-818$.

22. de Graaf, E.M., M. Oosterveld , T. Tjabbes and B.H.Stricher (1996): A case of tiazindine - induced hepatic injury, J. Hepatol., 25 (5) : $772-773$.
23. David, A.O. (2005): Head Injury-eMe dicine, Neurological Emergencies ,pp.1-10.

24. Donahoe, R. M. (1990): Drug abuse and AIDS: Causes for the connection. In Pharm. PTK, Rice K Eds: Drug of abuse : Chemistry, pharmacology, Immunology and AIDS. NIDA research monograph , 96: 181-190,GPO, Washington,DC.

25. Drug Facts and Comparisons. St Louis: Facts and Comparisons, 2001.

26. Drury, R.A. and E.A. Wallington (1979): Carletons histological technique sth Ed. Oxford medical publication plytmouth and London 194.

27. Drury, R.A. and E.A. Wallington (1980): Carletons histological technique sth Ed. Oxford University, New York, Toronto, London: 140-142 .

28. Elaine H. S.; D. Janet ; H. Richard ; Sue Burkhart-Kasch and J.P. Tamara (1998): Seizure Sensitivity and GABAergic Modulation of Ethanol Sensitivity in Selectively Bred FAST and SLOW Mouse Lines Vol. 287, Issue 2, 606-615.

29. Endmann, M. and Kutz R.(2005): Baclofen-intoxication in a child resulting in coma, bradycardia and transitory defect of visual power. Kinderklinik, Marienhospital Witten. fam.endmann@ freenet.de.

30. Ermis B. , A. Yildirim, R.Ors, A. Tastekin, B.Ozkan and F.Akeay (2005): Influence of smoking on serum and milk malodialehyde, superoxide dismutase, glutathione peroxidase, and antioxidant potential levels in mothers at the postpartum seventh days. Boil . Trace Elem. Res. , 105 (1-3) :27-36 .

31. Fattore, L.; G. Cossu; M.C. Martellotta; S.Deiana and W. Fratta (2001): Baclofen antagonises intravenous self-adm-inistration of gamma-hydroxybutyric acid in mice. Neuroreport 12, 2243-2246.

32. Fattore, L.; G. Cossu; M.C Martellotta and W. Fratta (2002): Baclofen antagonise intravenous self-administration of nicotine in mice and rats. Alcohol and Alcoholism 37, 495-498.

33. Gracies, J. M.; P. Nance; E. Elovic; J. Mc Guire and D.M.Simpson(1997): Traditional pharmacological treatments for spasticity. Part II: General and regional treatments. Muscle-Nerve-Supply; 6: S92-120.

34. Guide book for controlled and uncontrolled drugs (2003), General Administration for Anti -narcotics ,Ministry of Interior, Cairo, Egypt .

35. Hardman, J.G.; L.E. Limbird; P.B. Molinoff; R.W. Ruddon and and A. G. 
Gilman(1996); (eds.): Goodman and Gilmans The Pharmacological Basis of Therapeutics, 9th ed. McGraw-Hill: New York, (pp. 307-360; 461-486).

36. Henderson R.F and K.J.Nikula (2001) :Tract toxicity in: Introduction to biochemical toxicology edited by Hodgson E and Smart R.C., Wiley Interscience, John Wiley and Sons , Inc. , Publication , $3^{\text {rd }}$ ed. Ch. 24 , pp. 612-616.

37. Herfindal,E.T. and D.R. Gourley (2000): Textbook of Therapeutics. Drug and Disease Management, 7th ed. Philadelphia: Lippincott Williams \& Wilkins, 2000. pp. 1107-1156.

38. Hodgson, E. and P.E.Levi (2001) :Reactive Metabolites and toxicity in Introduction to biochemicals toxicology edited by Hodgson E and Smart R.C. , Wiley Interscience, John Wiley and Sons, Inc., Publication, $3^{\text {rd }}$ ed. Ch. 9, PP.213-216

39. Illum N.O. ,F.J. Hanson, C.Fischer , P.V.Uldall and O.A. Nielsen (2003): Intrathecal baclofen in thetreatment of severe spastic tetraplegia and dystonia in children and adolescents . Ugeskr Laeger, 165 (17) : 1755 - 1759 .

40. Kalashnikov, S.V. ; E.A. Kalashnikova and S.N. Kokarovtseva (2002): immunomodulating effects of tofizopam (Grandaxin) and diazepam in Vitro. Mediators of Inflammation.11(1): 53-59.

41. Kalivas, P. W.; Duffy, P. and Eberhardt, H. (1990): Modulation of A10 dopamine neurons by -aminobutyric acid agonists. Journal of Pharmacology and Experimental Therapeutics 253, 858-866.

42. Karch, S.B.(1993): The pathology of drug abuse, CRC Press, Boca Raton, FL.

43. Karch, A.M. (2000): Focus on Nursing Pharmacology. Philadelphia: Lippincott. Chapters 21-23, pp. 254-288.

44. Katzung, B.G.(2001): Basic and Clinical Pharmacology, 8th ed. Appleton \& Lange: Norwalk, CT. (pp. 395-462).

45. Klemm, W.R.(1969): Animal electroencephalography. New York, Academic Press, Inc.: 1-217.

46. Klemm,W.R.(1992): Are there EEG correlates of mental states in animals. Neuropsychobiology; 26:151-165.

47. Klinika,I ; W.I. Chorob ; Z. Ostrych ; M. Akademii and W. Gdansku (2005): Acute intoxication with baclofen Wisniewski M.Drug Supplier Biz Muscle Relaxants Relaxers Drugs Pharmacy for Muscle Relaxants Relaxers Flexeril, Cyclobenzaprine, Skelaxin.htm.
48. Koul, A. , V.Bhatia and M.P. Bansal (2001) :Effect of alpha -tocopherol on pulmonary antioxidant system and lipid peroxidation in cigarette smoke inhalation, BMC Biochem. , 2-14 .

49. Krusz,J.C., B.R.N. Jeanne and M. Corbin (2000): Headache M.S.N., A.N.P. 11:41 45.

50. Kuhn, M.A.(1998): Pharmacotherapeutics: A Nursing Process Approach, 4th ed. F.A. Davis: Philadelphia. (pp. 277-346).

51. Kuppusamy UR., M. Dharmani, M.S. Kanthimathi and M.Indran (2005): Antioxidant enzyme activities of human peripheral blood mononuclear cells exposed to trace elements, Biol. Trace Elem. Res. , 106 (1): 29:40.

52. Landau, W.M.(1995): Tizanidine and spasticity. Neurology; 45(12): 2295-6.

53. Leite-Morris, K. A.; E.Y. Fukudome and G.B.Kaplan (2002): Opiate-induced motor stimulation is regulated by $\gamma$-aminobutyric acid type $B$ receptors found in the ventral tegmental area in mice. Neuroscience Letters 317, 119-122.

54. Lehmann, A.; M. Antonsson ; M. Bremner-Danielsen ; M. Flardh ; L. Hansson-Branden and L.Karrberg (1999): Activation of the GABA(B) receptor inhibits transient lower esophageal sphincter relaxations in dogs. Gastroenterology; 117:1147-1154.

55. Lehmann, A.; M. Bremmer-Danielsen ; 1. Hansson-Branden ; l. Karrberg and M. Wilson (2000): Inhibitory effects of baclofen on transient lower esophageal sphincter relation in the dog after intracerebroventricular but not after intrathecal administration of baclofen . Gastroenterology ;118:A130.

56. Levy, J.A. (1989): Human immunodeficiency viruses and the pathogensis of AIDS. JAMA., 261: 2997-3006.

57. Li, S.M.;L.L. Yin; Y.H. Ren; L.S. Pan and J.W. Zheng (2001): $\mathrm{GABA}_{\mathrm{B}}$ receptor agonist baclofen attenuates the development and expression of d-methamphetamine-induced place preference in rats. Life Sciences 70, 349-356.

58. Ling, W.; S. Shoptaw and D. Majewska (1998): Baclofen as a cocaine anti-craving medication: a preliminary clinical study. Neuropsychopharmacology 18, 403-404.

59. Lidums, I.; A. Lehmann ; H. Checklin; J. Dent and R.H. Holloway (2000): The $\mathrm{GABA}_{\mathrm{B}}$ agonist baclofen inhibits transient lower esophageal sphincter relaxations and 
gastroesophageal reflux in normal human subjects. Gastroenterology;118:7-13.

60. Mandema, JW.; C.D. Heijligers-Feijen; E. Tukker; A.G.De Boer and M. Danhof, (1992): Modeling of the effect site equilibration kinetics and pharmacodynamics of racemic baclofen and its enantiomers using quantitative EEG effect measures. Modeling of the effect site equilibration kinetics and pharmacodynamics of racemic baclofen and its enantiomers using quantitative EEG effect measures

61. Mediratta , P.K. and K.K. Sharma (2002): Differential effects of benzodiazepines on immune responses in nonstressed and stressed animals. Indian Journal of Medical Sciences.56(1) : 9-15.

62. Menon, M. K.;W.G. Clark and C. Vivonia (1980): Interaction between phencyclidine (PCP) and gaba-ergic drugs: clinical implications. Pharmacology, Biochemistry and Behavior 12, 113-117.

63. Mosmann,T.(1983): Rapid colorimetric assay for cellular growth and survival: Application to proliferation and cytoto-xicity assay.J. Immunology. Meth.65,55-63.

64. Miyamoto, M.D. (2004): Agents Affecting neuromuscular Transmission in , Modern pharmacology with clinical applications, Craig CR. and Stitzel RE. (eds), Lippincott Williams and Wilkins, $6^{\text {th }}$ ed., Ch.28,p. 344.

65. Mycek, M.J.;R.A. Harvey and P.C. Champe (1997): Lippincottes Illustrated Reviews:Pharmacology,2nd ed. LippincottRaven:Philadelphia.(pp.107-118, 143-150).

66. Meythaler J.M.; S. Guin-Renfroe and P. Grabb, et al.(1999): Long-term continuously infused intrathecal baclofen for spastic- dystonic hypertonia in traumatic brain injury: 1-year experience. Arch Phys Med Rehabil ; 80(1): 13-9.

67. Nabila, A.; S. Hassan; M.W.Kadry; A. Hanaah and A.A.W. Mosaad(2001): Effects of antioxidants on oxidative stress of pyriproxyfen in female rats. The Medical J. of Cairo University, 69(1):79-90.

68. Paget, G.E.and J.M. Barnes (1964): Evaluation of drug activities and pharmacometrics. Editors Laurence, D.R. and Bacharach, A.L. Academic Press, London, 1:135-166.

69. Paglia D.E. and W.N.Valentine (1967): Studies on quanlitative and qualita-tive Characterization of erythrocyte glutathione peroxidase, J. Lab. Clin. Med., 70: $158-169$.

70. Phillis, B. D.; J. Ong ; J.M. White and C.
Bonnielle (2001): Modification of $d$ amph-etamine-induced responses by baclofen in rats. Psychopharmacology 153, 277-284.

71. Ramseier, H.; W. Lichtensteiger and $M$. Schlumpf (1993): In vitro inhibition of cellular immune responses by benzodiazepines and $\mathrm{Pk}$ 11195. Immuno Pharmacology Immuntoxicol., 15:557-582.

72. Reed, D.J. (2001) :Mechanisms of chemically induced cell injury and cellular protection mechanisms in : Introduction to biochemical toxicology edited by Hodgson E and Smart R.C. , Wiley Interscience, John Wiley and Sons, Inc. , Publication, $3^{\text {rd }}$ ed. Ch. 10 , pp. $241-252$.

73. Rode G. , E. Maupas , J.Luaute , S.Courtois - Jacquin and D. Boisson (2003): Medical treatment of spasticity. Neurochirurgie, 49 (2-3 pt2) 247 -255.

74. Saleh ,M.A. and H.S. El-Kashef (1982): Effect of chemical radioprotection on changes in EEG patterns conduced in whole body gamma irradiated rats,II. Chronic changes. Proceedings the first National Conference Biophysical and Bioengineering Sciences, 172,Cario.

75. Saleh, M. A.; K.M. Tohamy and M. I. El-Gohary (1983): Electrical activity of hippocampal neuronal circuit. Egyptian J. Biomedical Engine. 4(1-2): 61-75.

76. Schaul,N.;I.Green and R. Peyster (1986): Structural determinants of Electro-encephalographic findings in acute hemispheric lesions. Ann Neurol ; 20(6): 703-11.

77. Schlumpf, M.; R. Parmar and A. Schreiber, et al.,(1990): Prenatal benzodiazepine immunosuppression: Possible involvement of peripheral benzodiazepine site.Dev. Pharmacology. Ther.,15:178-185.

78. Schlumpf,M.;R.Parmar and A. Schreiber, et al.(1992): Nervous and immune system as targets for developmental effects of benzodiazepines. Dev. Pharmacology. Ther., 18: 145-158.

79. Skinner, J.E. (1971): Neuroscience, Laboratory Manual. W.B. Saunder Company, Philadelphia, London Tenant 87.

80. Sos I., N.Kiss ,J. Csorba and J. Gerevich (2000): Tizanidine in the treatment of acute withdrawal symptoms in heroin dependent patients.Orv. Hetil., 141 (15): 783- 786.

81. Sphelmann,R.(1980):EEG Primer.Elsevier Biomedical presses. Amsterdam.New York. Oxford.

82. Strivastava, P.K.;V.K. Chaudhary; S.S. Chauhan; V.K. Strivastava and U.K. 
Misra(1984): Biochemical and pathological effects of fly Ash on lung, liver, and blood of rats. Arch, Environ. Contam. Toxicology. 441-452.

83. Suttle, N.F. (1986): The Veterinary record. 119:519-522 .

84. Tietz N.w. (1986) : Text book of clinical chemistry W.B. Saunders company, pp. $960-962$.

85. Tietz N.W. (1986) : Text book of clinical chemistry W.B. Saunders company, pp. $1508-1510$.

86. Tsuji, M.;Y. Nakagawa; Y. Ishibashi; T. Yoshii ; T. Takashima ; M. Shimada and T.Suzuki (1996): Activation of ventral tegmental $\mathrm{GABA}_{\mathrm{B}}$ receptors inhibits morphine -induced place preference in rats. European Journal of Pharmacology 313, 169-173.

87. USPDI, Vol. I, 19th ed., Englewood, CO:Micromedex, Inc. 1999.

88. Varley H. ,A.H.Gowen lock and M.Bell (1981) : Prachcal clinical biochemistry, William Heinemann Medical books LTD , London, $5^{\text {th }}$ ed . Vol.2, pp. $222-223$.

89. Wagner, P.G. and M.S. Dekin (1993): GABA_B receptors are coupled to a barium-insensitive outward rectifying potassium conductance in premotor respiratory neurones. J Neurophysiology;(69), 286-289

90. Wagner, P.G. and M.S. Dekin (1997): cAMP modulates an S-type $\mathrm{K}+$ channel coupled to GABA-B receptors in mammalian respiratory neurones. Neuroreport., (8), 1667-1670.

91. Wagstaff, A.J. and H.M. Bryson (1997) : Tizanidine. A review of its pharmacology, clinical efficacy and tolerability in the management of spasticity associated with cerebral and spinal disorders. Drugs, 53 (3): 435-52 .

92. Wang, J. K., J. Morgan and S. Spector (1984): Benzodiazepines that bind at peripheral sites inhibit cell proliferation. Proc. Natl. Acad. Sci., 81: 753-756.

93. Wise, R. A. and M.A. Bozarth (1987): A psychomotor stimulant theory of addiction. Psychological Reviews 94, 469-492.

94. Woo, S.H.; H.S. Kim; J.S. Yun; M.K. Lee; K.W. Oh; Y.H. Seong; S.K. Oh and C.G.Jang (2001): Inhibition of baclofen on morphine-induced hyperactivity, reverse tolerance and postsynaptic dopamine receptor supersensitivity.Pharmacological Rese -arch 43, 335-340.

95. Wood, L.G. ,P.G Gibson and M.L.Garg (2003):Biomakers of lipid peroxidation, air way inflammation and asthma, Eur. Respir. J. , $21: 177-186$.

96. Xi,Z.X.and E.A.Stein(2002): GAB Aergic mechanisms of opiate reinfor-cement. Alcohol and Alcoholism 37,485-494. 


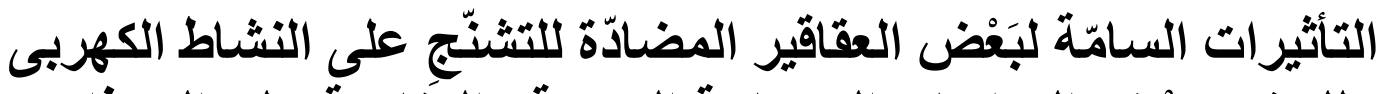

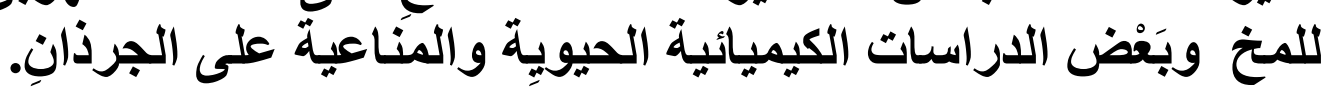

$$
\text { فتحى عباس قناوى - إيناس الجعراوى - حنان مصطقى المركز القومى للبحوث الاجتماعية والجنائية }
$$

تمت در اسة سمية عقارى التيز انيدين و الباكلوفن فى ذكور الجرذانِ، حيث

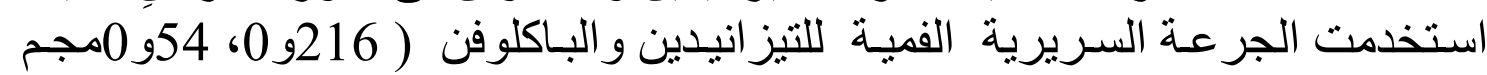

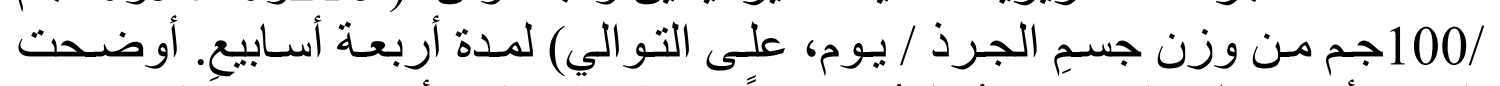

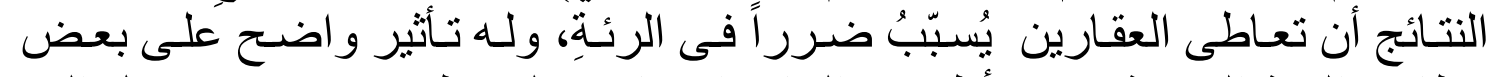

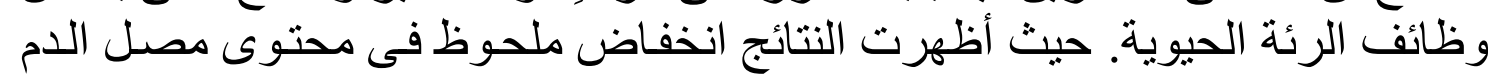

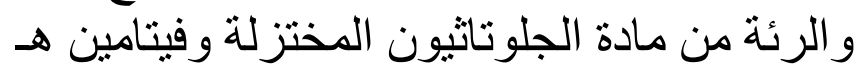

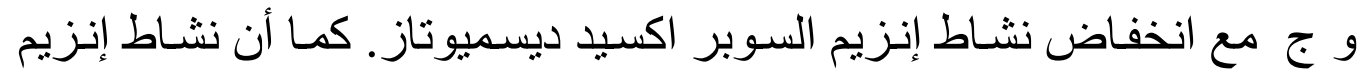

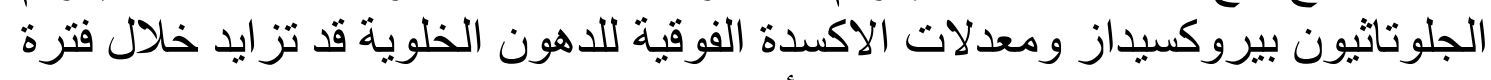

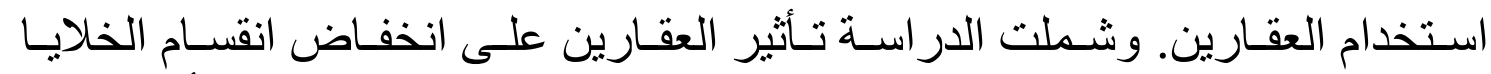

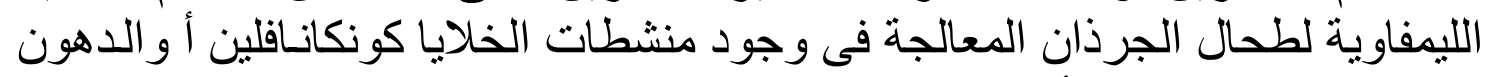

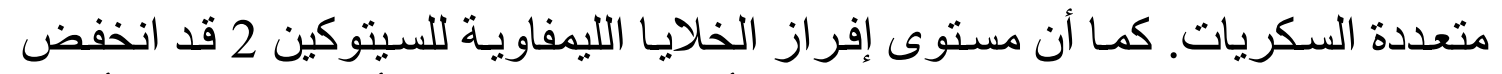

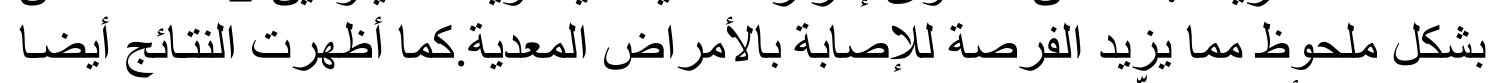

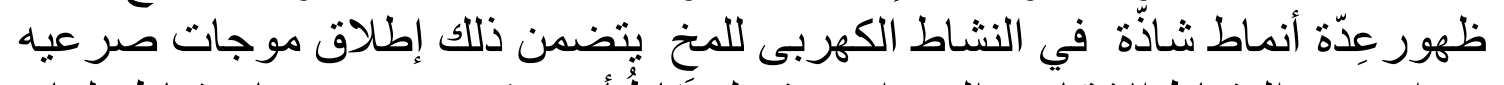

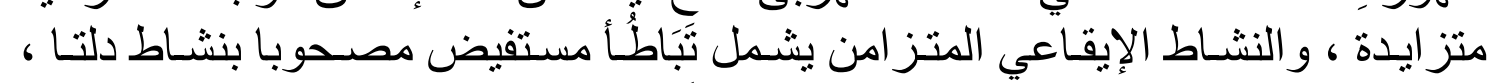

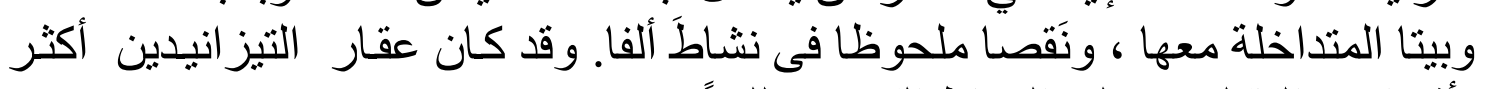

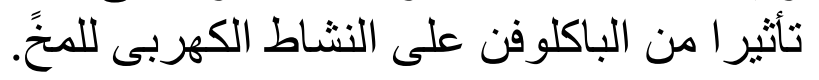

